\title{
Passive Facebook Usage Undermines Affective Well-Being: Experimental and Longitudinal Evidence
}

\author{
Philippe Verduyn \\ University of Leuven
}

\author{
David Seungjae Lee, Jiyoung Park, Holly Shablack, \\ Ariana Orvell, Joseph Bayer, Oscar Ybarra, \\ John Jonides, and Ethan Kross \\ University of Michigan, Ann Arbor
}

\begin{abstract}
Prior research indicates that Facebook usage predicts declines in subjective well-being over time. How does this come about? We examined this issue in 2 studies using experimental and field methods. In Study 1, cueing people in the laboratory to use Facebook passively (rather than actively) led to declines in affective well-being over time. Study 2 replicated these findings in the field using experience-sampling techniques. It also demonstrated how passive Facebook usage leads to declines in affective well-being: by increasing envy. Critically, the relationship between passive Facebook usage and changes in affective well-being remained significant when controlling for active Facebook use, non-Facebook online social network usage, and direct social interactions, highlighting the specificity of this result. These findings demonstrate that passive Facebook usage undermines affective well-being.
\end{abstract}

Keywords: Facebook, social support, well-being, envy, online social networks

Just a decade ago people primarily relied on face-to-face interactions, the phone, and e-mail to connect. Today, such connections often occur instantly via online social networks such as Facebook-but to what effect on well-being?

Kross et al. (2013) addressed this issue by examining the longitudinal implications of Facebook use for the two components of subjective well-being: how people feel moment-to-moment and how satisfied they are with their lives. They found that the more people used Facebook during one time period, the worse they subsequently felt; the more they used Facebook over 2-weeks, the more their life satisfaction levels declined over time.

Although these findings begin to illuminate the relationship between Facebook usage and subjective well-being, they raise an important question: How does Facebook usage lead to these de-

This article was published Online First February 23, 2015.

Philippe Verduyn, Department of Psychology, University of Leuven; David Seungjae Lee, Jiyoung Park, Holly Shablack, and Ariana Orvell, Department of Psychology, University of Michigan, Ann Arbor; Joseph Bayer, Department of Communication Studies, University of Michigan, Ann Arbor; Oscar Ybarra, John Jonides, and Ethan Kross, Department of Psychology, University of Michigan, Ann Arbor.

This research was supported by funds provided by the University of Michigan to EK and a postdoctoral research fellowship to PV from the Fund for Scientific Research-Flanders (FWO). Author contributions: Conceived and designed Study 1: PV, DSL, JP, JB, HS, AO, OY, JJ, EK; conceived and designed Study 2: PV, DSL, JP, HS, JB, OY, JJ, EK; performed Study 1: DSL, HS, AO; performed Study 2: HS; analyzed the data: PV, DSL; wrote the article: PV, DSL, AO, EK; discussed the results and commented on the manuscript: PV, DSL, JP, HS, AO, JB, JJ, EK.

Correspondence concerning this article should be addressed to Philippe Verduyn, Tiensestraat 102 - box 3713, 3000 Leuven, Belgium, or Ethan Kross, 530 Church Street, Ann Arbor, MI 48109. E-mail: philippe.verduyn@ ppw.kuleuven.be or ekross@umich.edu clines? We addressed this question by examining whether the way people use Facebook, in particular whether they do so actively or passively, explains how this technology impacts subjective wellbeing.

Prior research indicates that Facebook activities can be dichotomized into active and passive forms of usage (Burke, Marlow, \& Lento, 2010; Deters \& Mehl, 2013; Krasnova, Wenninger, Widjaja, \& Buxmann, 2013). Active usage refers to activities that facilitate direct exchanges with others (e.g., posting status updates, commenting on posts); passive usage involves consuming information without direct exchanges (e.g., scrolling through news feeds, viewing posts). This distinction is important because crosssectional work has linked passive Facebook usage with reduced levels of subjective well-being (Krasnova et al., 2013).

Why might passive Facebook usage undermine well-being? On Facebook, people tend to portray themselves in overly flattering ways (Barash, Ducheneaut, Isaacs, \& Bellotti, 2010; Kross et al., 2013; Mehdizadeh, 2010; Newman, Lauterbach, Munson, Resnick, \& Morris, 2011). They also communicate positive life developments more frequently than negative ones (Kross et al., 2013). Theoretically, continually exposing oneself to positive information about others should elicit envy, an emotion linked to lower well-being (Salovey \& Rodin, 1984; Smith \& Kim, 2007). Although some cross-sectional evidence supports this idea (Chou \& Edge, 2012; Krasnova et al., 2013), experimental and longitudinal evidence is needed to demonstrate whether it is true.

In sum, previous research suggests that Facebook use negatively influences subjective well-being. However, the mechanisms that underlie this relationship are not well understood. Does the way that people use Facebook, in particular whether they do so passively or actively, differentially impact subjective well-being? If so, what role does envy play in explaining how passive Facebook usage in particular negatively impacts subjective well-being? The 
cross-sectional design used to address these questions in prior work and exclusive focus on the cognitive component of subjective well-being (e.g., life satisfaction) makes it difficult to answer these questions definitively.

Here we aimed to fill these knowledge gaps by using a combination of laboratory and experience sampling methods to illuminate how Facebook use impacts subjective well-being. In Study 1, we manipulated whether participants used Facebook passively or actively in the laboratory, and examined the immediate and delayed effects of this manipulation on subjective well-being. In Study 2, we performed a 1-week experience sampling study to examine how active versus passive Facebook use impacts subjective well-being over time in daily life.

\section{Study 1}

\section{Method}

Participants. Eighty-four undergraduate students $\left(M_{\text {age }}=\right.$ $19.93, S D_{\text {age }}=4.20 ; 52$ females; $79 \%$ European American, $16 \%$ Asian, $1 \%$ Middle Eastern, 2\% African American, 2\% other) were randomly assigned to an active $(N=42)$ or passive $(N=42)$ Facebook use condition in exchange for course credit. Participants had to have an active Facebook account to participate. The University of Michigan institutional review board approved this study. We aimed for at least 35 participants per condition. The research coordinator was thus told to stop running the study after approximately 80 participants.

Baseline measures. Upon arrival in the laboratory, participants were seated in front of a computer where they remained for the entirety of the initial session. The session began with participants rating their affect ("How do you feel right now?" $0=$ very negative, $100=$ very positive; $M=67.77, S D=18.52$ ); loneliness ("How lonely do you feel right now?" 0 = not at all lonely, $100=$ very lonely; $M=34.22, S D=23.30)$; and life satisfaction $(M=$ 5.09, $S D=1.24, \alpha=.89$; Diener, Emmons, Larsen, \& Griffin, 1985).

Table 1

Cover Story and Manipulation Instructions for Study 1
We also assessed participants' motivation for using Facebook by asking them to indicate whether they use Facebook to keep in touch with friends (77\% answered yes), to find new friends (13\% answered yes), to share good things with friends (52\% answered yes), to share bad things with friends (7\% answered yes), to obtain new information (68\% answered yes), or other: please explain (20\% answered yes). Examples of other reasons included keeping in touch with family and organize photos.

Additional measures were administered during this session for filler and/or exploratory purposes. The measures reported here are those that were theoretically motivated and directly informed by our previous research (Kross et al., 2013).

Experimental manipulation. After completing the baseline measures, participants were randomly assigned to use Facebook actively or passively for $10 \mathrm{~min}$. The experimenter explained that active Facebook use involved posting and communicating with others on Facebook-for example, posting status updates or sharing links, reacting and commenting on friends' posts or private messages; passive Facebook use involved browsing Facebook-for example, scrolling through news feeds, looking at friends' pages and pictures, or a band's page. Participants in the active condition were instructed to use Facebook actively and refrain from using it passively; those in the passive condition received the opposite instructions (for verbatim instructions, see Table 1).

Compliance. To ensure that participants followed protocol, we recorded, unbeknownst to participants, their screen while they were using Facebook with a software program called TeamViewer. Nine participants (five in the active condition, four in the passive condition) did not follow instructions (e.g., using Facebook actively when instructed to use it passively). They were excluded from all analyses.

Postmanipulation questionnaire. After the 10-min Facebook usage period was complete, the experimenter returned to the lab and instructed the participant to complete another brief online questionnaire via Qualtrics, which asked participants to rate their
Although there are many factors that contribute to Facebook's popularity, some studies suggest that one of the key reasons for Facebook's popularity is that it allows people to browse their social world conveniently. By browsing, we mean scrolling through one's news feed, looking at one's friends' pages, pictures, and status updates. Many people report that through browsing, they can easily connect to and experience their social world.

So for the next $10 \mathrm{~min}$, we ask that you try using Facebook only for browsing: for example, scrolling through your news feed, looking at your friends' pages, pictures, and status updates, or a band's page, etc. In addition, we ask that you only use Facebook for browsing and refrain from other activities, such as posting statuses, sharing links, reacting and commenting on friends' walls, or sending messages.

While you are browsing we ask that you refrain from clicking on any links that will lead to non-Facebook sites.
Although there are many factors that contribute to Facebook's popularity, some studies suggest that one of the key reasons for Facebook's popularity is that it allows people to have direct communication with others conveniently-by direct communication, we mean posting status updates, sharing links, reacting and commenting on friends' walls, or sending messages. Many people report that through direct communication, they can easily connect to and experience their social world.

So for the next 10 min, we ask that you try using Facebook only for direct communication: for example, posting status updates, sharing links, reacting and commenting on friends' walls, or sending messages. In addition, we ask that you only use Facebook for direct communication and refrain from other activities, such as browsing, scrolling through your news feed, looking at your friends' pages, pictures, and status updates, or a band's page, etc.

While you are browsing we ask that you refrain from clicking on any links that will lead to non-Facebook sites.

Note. Bolded text reflects aspects of the manipulation that differed between conditions. 
current mood ( $\mathrm{T}_{2}$ affect, $\left.M=69.51, S D=17.18\right)$; how lonely they felt ( $\mathrm{T}_{2}$ loneliness, $M=27.89, S D=21.30$ ); how connected to others they felt $\left(\mathrm{T}_{2}\right.$ connected, $0=$ not at all connected, $100=$ very connected, $M=58.74, S D=21.56)$; and how much better $\left(\mathrm{T}_{2}\right.$ better, $0=$ not at all better, $100=$ better, $M=54.41, S D=$ $26.54)$ or worse $\left(\mathrm{T}_{2}\right.$ Worse, $0=$ not at all worse, $100=$ worse, $M=21.99, S D=22.11)$ they thought their life seemed compared to others. Because the latter two items both reflected how participants viewed their own life compared with others', we averaged (reverse-coded $\mathrm{T}_{2}$ better) them so that higher scores reflected the tendency to view one's life as worse off than other people $(r=.48$, $M=33.76, S D=20.86$ )

Funneled debriefing and end-of-day instructions. Next, a funneled debriefing was administered to determine whether participants were aware of why we manipulated their Facebook usage. Eight participants (three in the active condition, five in the passive condition) were aware of the study hypotheses and were thus excluded from all analyses on a priori grounds leaving 67 participants ( 34 in the active and 33 in the passive condition).

Participants were also asked whether they believed they were watched while using Facebook. Nine participants reported suspicion in this regard. As we had no predictions on the possible effect of suspicion on our results we did not exclude these participants. Nevertheless, it is notable that the conclusions remained identical with or without these participants.

At this point participants were notified that the in-laboratory session was complete. They were told that they would receive a follow-up survey in the evening ( 9 p.m.), which they were asked to complete upon receipt.

End-of-day questionnaire. Participants received a follow-up survey at 9 p.m. All but four participants (two from each condition) completed the survey $(95.2 \%)$. Another four participants initially forgot to complete the follow-up survey and completed it during the days following the experiment instead. Excluding these participants from the analyses did not substantively influence the results. The average time elapsed between the in-laboratory session and the end-of-the-day questionnaire was $9.04 \mathrm{hr}(S D=$ 11.52). Controlling for the elapsed time did not substantively influence the results.

The survey included all items from the post manipulation questionnaire $\left(\mathrm{T}_{3}\right.$ affect, $M=67.05, S D=21.06 ; \mathrm{T}_{3}$ loneliness, $M=25.77, S D=23.30 ; \mathrm{T}_{3}$ connected, $M=61.84, S D=$ $20.28 ; \mathrm{T}_{3}$ better, $M=59.99, S D=21.02 ; \mathrm{T}_{3}$ worse, $M=25.66$, $S D=22.39$ ). In addition, to assess potential lagged effects of active versus passive Facebook usage on cognitive well-being, we administered the Satisfaction with Life Scale again $\left(\mathrm{T}_{3}\right.$ SWLS, $M=5.26, S D=1.20, \alpha=.90)$.

Finally, for exploratory purposes we also asked participants how much they used Facebook actively $\left(\mathrm{T}_{3}\right.$ active Facebook use, $M=22.61, S D=25.05)$ and passively $\left(\mathrm{T}_{3}\right.$ passive Facebook use, $M=49.20, S D=30.28$ ), and to indicate the degree to which they used other non-Facebook online social network sites actively $\left(\mathrm{T}_{3}\right.$ non-Facebook active social network use, $M=$ $32.78, S D=30.86)$ and passively $\left(\mathrm{T}_{3}\right.$ non-Facebook online social network use, $M=39.78, S D=33.93$ ) since they left the lab.

\section{Results}

We examined the effect of type of Facebook usage on affective well-being ("How do you feel right now?") by performing a 2 (Facebook Use: Active vs. Passive) $\times 3$ (Time of Assessment: Baseline vs. Post Manipulation vs. End of Day) repeated measures Analysis of Variance (ANOVA). This analysis revealed a significant interaction, $F(2,126)=4.04, p=.02, \eta_{\rho}^{2}=.06$, uncorrected; $F(1.61,101.1)=4.04, p=.03, \eta_{\rho}^{2}=.06$, Greenhouse-Geisser corrected. ${ }^{1}$ As Figure 1 and Table 2 illustrate, neither passive use nor active use participants displayed changes in affect immediately following the manipulation. However, passive use participants displayed a significant drop in affective well-being at the end of the day relative to both their baseline and postmanipulation affect levels; active use participants did not. The two groups also differed significantly on end of the day affect, $t(126)=-3.07, p<.01$, $95 \%$ CI $[-16.78,-3.66]$. Gender did not moderate the effect of type of Facebook usage on affective well-being across time, $F(2$, $122=.31, p=.73, \eta_{\rho}^{2}=.01$ uncorrected; $F(1.61,98.10)=.31$, $p=.69, \eta_{\rho}^{2}=.01$, Greenhouse-Geisser corrected.

Although we expected passive Facebook usage would lead participants to view their own life as worse compared to others, a 2 (Facebook Use) $\times 2$ (Time of Assessment: Postmanipulation vs. End of the Day) repeated measures ANOVA on this variable did not reveal a significant effect of condition or condition by time interaction $(F \mathrm{~s}<1.32, p \mathrm{~s}>.25)$. The complementary analysis performed on life satisfaction likewise failed to reveal any significant effects involving condition $\left(F_{\mathrm{s}}<1.76, p \mathrm{~s}>.19\right)$. We did, however, observe a significant effect of time on life satisfaction, $F(1,63)=6.96, p=.01, \eta_{\rho}^{2}=.10,95 \%$ CI $[.04, .25] ;$ participants scored higher on this measure at the end of the day compared to baseline. This increase was not related to any type of social media usage that we assessed $(F \mathrm{~s}<1.55, p \mathrm{~s}>.21){ }^{2}$

Note that unlike affective well-being (described earlier), both of these measures were administered twice (not three times) to reduce the likelihood that participants would discern the goals of the study, which is also why $2 \times 2$ ANOVAs were performed.

Finally, the experimental manipulation did not influence how much participants reported using Facebook overall, $F(1,63)=.16$, $p=.69, \eta_{\rho}^{2}=.003,95 \%$ CI $[-15.17,10.11]$; or how actively, $F(1$, $63)<.001, p=.98, \eta_{\rho}^{2}<.001,95 \%$ CI $[-11.71,11.97]$; or passively, $F(1,63)=.37, p=.55, \eta_{\rho}^{2}=.006,95 \%$ CI $[-19.65$, 10.53] they used Facebook after they left the lab. It did, however, influence how much people reported using non-Facebook online social networks. Specifically, participants in the passive condition

\footnotetext{
${ }^{1}$ Mauchly's Test of Sphericity indicated that the assumption of sphericity had been violated, $\chi^{2}(2)=17.54, p<.0001$, therefore degrees of freedom were corrected using Greenhouse-Geisser estimates of sphericity $(\varepsilon=.80)$.

${ }^{2}$ Although our study focused on how type of Facebook usage influences the two components of subjective well-being (affect and life satisfaction), we also measured loneliness and social connection because some research has linked active Facebook usage with changes in these constructs (Deters $\&$ Mehl, 2013). Neither the main effect of condition nor the Condition $\times$ Time interaction was significant for these variables $(F \mathrm{~s}<.51, p \mathrm{~s}>.52)$. However, the effect of time was significant for loneliness, $F(2,118)=$ $8.60, p<.001, \eta_{\rho}^{2}=.13$ ); all participants felt less lonely at the second, $t(118)=-3.25, p<.01,95 \%$ CI $[-12.80,-3.10]$ and third assessment, $t(118)=-3.86, p<.001,95 \%$ CI $[-14.29,-4.60])$ compared with baseline.
} 


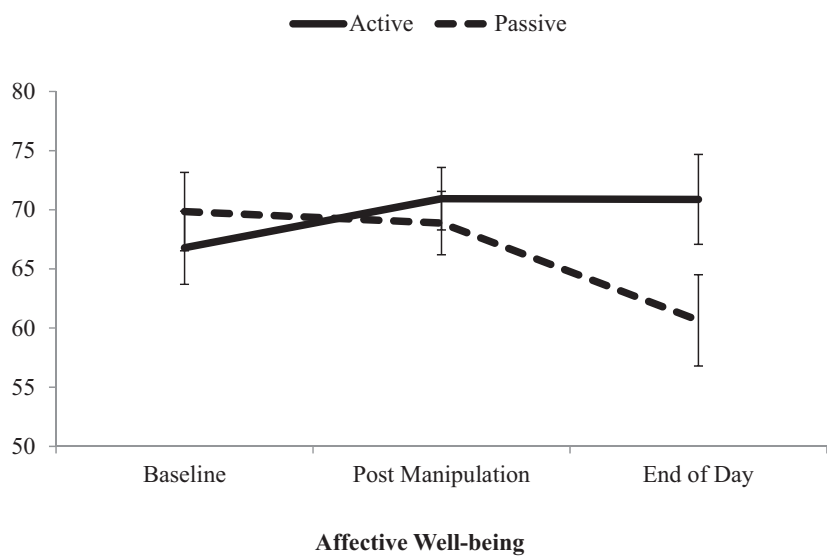

Figure 1. Affective well-being over time as a function of passive vs. active Facebook use. Error bars represent $+/-1$ standard error.

reported engaging more in active, $F(1,63)=5.12, p=.03, \eta_{\rho}^{2}=$ $.08,95 \%$ CI $[2.02,32.69]$; and passive, $F(1,63)=5.01, p=.03$, $\eta_{\rho}^{2}=.07,95 \%$ CI $[2.04,35.80]$ forms of non-Facebook online social interaction (e.g., Tumblr, Twitter, Blogger, MySpace, Instagram) after they left the lab. Critically, controlling for these other types of non-Facebook online social network use did not substantively influence any of the aforementioned results.

\section{Study 2}

Study 1 demonstrated that passive Facebook usage decreases affective well-being, but not life satisfaction. Study 2 examined whether passive Facebook usage predicts similar outcomes when people engage in this behavior spontaneously in daily life. It also investigated the psychological mechanism underlying the link between passive Facebook usage and affect. In Study 1, we did not observe an effect of type of Facebook usage on people's tendency to view their life as worse off than others, which we thought would exacerbate envy and lead to emotional declines. One explanation for this null finding is that participants may not have been aware of whether they compared their life to others (Brickman \& Bulman, 1977; Gilbert, Giesler, \& Morris, 1995; Goethals, 1986; Nisbett \& Wilson, 1977; Wood, 1996). Consequently, it is possible that people did engage in this comparison process, but our measurement strategy may have failed to capture it. Study 2 circumvented this issue by examining whether passive Facebook usage influenced envy, a consciously accessible subjective experience (Ellsworth, 1995; Robinson \& Clore, 2002) that we thought would be a more proximal predictor of affective well-being.

We examined these issues in Study 2 by text messaging participants five times a day for 6 days. Each text contained a link to an online survey, which asked participants to answer questions that assessed affective well-being, envy, active Facebook usage, passive Facebook usage, direct social interaction, and non-Facebook online social network usage (for question items, see Table 3). We performed lagged analyses on participants' responses to these questions and their answers to the Satisfaction With Life Scale (Diener et al., 1985), which they completed before and after the experience-sampling phase of the study, to examine whether type of Facebook usage predicts changes in affective and cognitive well-being over time.

\section{Method}

Participants. Eighty-nine people $\left(M_{\text {age }}=20.23, S D_{\text {age }}=\right.$ 2.10; 61 females; 53\% European American, 34\% Asian, 8\% African American, and 5\% other) were recruited for a study about Facebook through flyers posted around Ann Arbor, Michigan. To qualify for the study participants had to possess a Facebook account and a touch-screen smartphone. They received up to $\$ 40$ and were entered into a raffle to receive an iPod Nano for participating. The University of Michigan institutional review board approved this study.

We determined our target sample size by referencing a recent experience sampling study on Facebook and well-being, which consisted of 82 participants (Kross et al., 2013). The research coordinator was told to stop running participants after approximately 80 participants were successfully run through the protocol.

Phase 1. Participants completed a set of questionnaires, which included the Satisfaction With Life Scale $(M=5.14, S D=1.08$, $\alpha=.85$; Diener et al., 1985), the Beck Depression Inventory $(M=$ $.43, S D=.37, \alpha=.90$; Beck, Ward, Mendelson, Mock, \& Erbaugh, 1961), the Revised UCLA Loneliness Scale $(M=1.72$, $S D=.51, \alpha=.92$; Russell, Peplau, \& Cutrona, 1980), the Rosenberg Self-Esteem Scale (Rosenberg, 1965; $M=2.68, S D=$ $.56, \alpha=.90)$, and the Social Provision Scale $(M=3.48, S D=.36$, $\alpha=.82$; Cutrona, 1989), which we modified to assess perceptions of Facebook support.

We also assessed participants' motivation for using Facebook by asking them to indicate whether they use Facebook to keep in touch with friends (95\% answered yes), to find new friends

Table 2

Simple Effects Demonstrating How the Passive and Active Facebook Conditions Affect Levels Fluctuate Over Time

\begin{tabular}{|c|c|c|c|c|c|c|}
\hline \multirow[b]{2}{*}{ Condition } & \multicolumn{2}{|c|}{$\begin{array}{l}\text { Postmanipulation vs. } \\
\text { baseline }\end{array}$} & \multicolumn{2}{|c|}{ End of day vs. baseline } & \multicolumn{2}{|c|}{$\begin{array}{l}\text { End of day vs. } \\
\text { postmanipulation }\end{array}$} \\
\hline & $t$ & $95 \% \mathrm{CI}$ & $t$ & $95 \% \mathrm{CI}$ & $t$ & $95 \% \mathrm{CI}$ \\
\hline Passive Facebook use & .29 & {$[-5.67,7.61]$} & $2.74^{* *}$ & {$[2.55,15.83]$} & $2.45^{*}$ & {$[1.58,14.86]$} \\
\hline Active Facebook use & -1.26 & {$[-10.69,2.39]$} & -1.24 & {$[-10.63,2.45]$} & .02 & {$[-6.48,6.60]$} \\
\hline
\end{tabular}

Note. Degrees of freedom for all tests is 126

${ }^{*} p<.05$. $^{* * *} p<.01$. $^{* * * *} p<.0001$. 
Table 3

Text Message Questions

\begin{tabular}{|c|c|}
\hline Variable & Question \\
\hline Affective well-being & How do you feel right now? \\
\hline Envy & $\begin{array}{l}\text { How envious have you been of others since } \\
\text { the last time we asked? }\end{array}$ \\
\hline Active Facebook use & $\begin{array}{l}\text { How much have you actively used Facebook } \\
\text { since the last time we asked? }\end{array}$ \\
\hline Passive Facebook use & $\begin{array}{l}\text { How much have you passively used Facebook } \\
\text { since the last time we asked? }\end{array}$ \\
\hline Direct social interaction & $\begin{array}{l}\text { How much have you interacted with other } \\
\text { people directly since the last time we } \\
\text { asked? }\end{array}$ \\
\hline $\begin{array}{l}\text { Non Facebook online } \\
\text { social networking use }\end{array}$ & $\begin{array}{l}\text { How much time have you spent on social } \\
\text { network sites other than Facebook since the } \\
\text { last time we asked? }\end{array}$ \\
\hline
\end{tabular}

Note. Participants rated their affective well-being on a $0=$ very negative to $100=$ very positive scale; all remaining questions used a $0=$ not at all to $100=$ a lot scale.

(19\% answered yes), to share good things with friends $(75 \%$ answered yes), to share bad things with friends (34\% answered yes), to obtain new information ( $76 \%$ answered yes), or other: please explain (14\% answered yes). Examples of other reasons included keeping in touch with family and playing games.

Phase 2. Participants were text-messaged five times per day between 10 a.m. and midnight for 6 consecutive days. Textmessages occurred at random times within five 168-min window blocks each day. Controlling for the length of time between any two text messages did not substantively influence the results. Each text-message contained a link to an online survey, which asked participants to answer questions on affective well-being and loneliness at the moment of completing the online survey, and degree of envy, active Facebook usage, passive Facebook usage, direct interactions, and non-Facebook social network usage since the previous report. The original affective well-being response scale ranged from $0=$ very positive to $100=$ very negative but ratings were reversed prior to analyses to match the response format of Study 1. Participants always answered the affect question first, followed by the loneliness question. The rest of the questions were presented randomly.

Prior to the start of the study, we operationalized active and passive Facebook usage for participants in the same way it was defined in Study 1. Subsequently, the experimenter walked participants through the protocol for answering each experiencesampling question to ensure that they understood how to respond to them.

On average, participants responded to $80 \%$ of the textmessages (range: 3\%-100\%). Following prior experience sampling research with a similar study duration (Koval, Kuppens, Allen, \& Sheeber, 2012) we pruned the data by excluding all of the data from nine participants who responded to $<60 \%$ of the texts, resulting in 2,084 total experience sampling observations from 80 participants. This threshold was more conservative than the one used in our prior work on Facebook and well-being (Kross et al., 2013) as the duration of the present study was shorter. Using the same cutoff score as we previously used did not alter the results.

Phase 3. Seventy-seven of the 80 participants that our analyses focused on returned to the laboratory following Phase 2 to complete another set of questionnaires, which included the Satisfaction With Life Scale $(M=5.06, S D=1.13, \alpha=.85$; Diener et al., 1985). We recorded participants' number of Facebook friends $(M=783.17, S D=425.19)$ and obtained a screenshot of their Facebook wall posts (so that we could record status updates) that corresponded to the timespan that the experience-sampling phase of the study took place during a subsequent session by asking them to $\log$ into their accounts in the presence of the experimenter. We were unable to obtain Facebook friend and/or wall data for 14 participants either because this information was hidden from their walls or because they did not return to have this information recorded. ${ }^{3}$

Analyses overview. Following prior work (Kross et al., 2013) we examined the relationship between active and passive Facebook usage and affect using multilevel analyses to account for the nested data structure. Specifically, we examined whether $\mathrm{T}_{2}$ affect (i.e., How do you feel right now?) was predicted by $\mathrm{T}_{1-2}$ active Facebook usage (i.e., How much have you used Facebook actively since the last time we asked?), or $\mathrm{T}_{1-2}$ passive Facebook usage (i.e., How much have you used Facebook passively since the last time we asked?), controlling for $\mathrm{T}_{1}$ affect at level-1 of the model. Note that although this analysis assesses Facebook usage at $\mathrm{T}_{2}$, the question refers to usage between $T_{1}$ and $T_{2}$ (hence the notation $T_{1-2}$ ). Thus, this analysis allowed us to explore whether active or passive Facebook usage during the time period separating $\mathrm{T}_{1}$ and $\mathrm{T}_{2}$ predicted changes in affect over time. Following prior work (Koval et al., 2012), we excluded between-day lags from the lagged analysis (i.e., participants first ratings in the morning were not predicted by their last ratings on the previous day).

When noncompliant cases were observed, we used participants' responses to the last text message they answered to maximize power when examining the lagged effect of type of Facebook usage on well-being. Thus, if we examined whether $\mathrm{T}_{2-3}$ active or passive Facebook usage predicted $\mathrm{T}_{3}$ affect controlling for $\mathrm{T}_{2}$ affect, but did not have data on $\mathrm{T}_{2}$ affect, then we used $\mathrm{T}_{1}$ affect instead. Excluding trials in which participants did not respond to the previous texts (rather than following this protocol) did not substantively alter any of the results we report.

All Level-1 predictors were group-mean centered, and intercepts and slopes were allowed to vary randomly across participants. Unstandardized regression weights are reported. Significance testing of fixed effects was performed using $t$ tests.

Degrees of freedom vary across analyses for the following reasons. For the nonlagged analysis 2,084 observations were used whereas for the lagged analysis only 1,609 observations were entered into the analysis (because between-day lags were excluded). When comparing the frequency of different types of communication (i.e., active Facebook, passive Facebook, non-

\footnotetext{
${ }^{3}$ Additional measures were included during Phases 1 and 3 either to serve as filler questionnaires or for exploratory purposes. The only measures that were administered during Phase 1 and Phase 3 (in addition to life satisfaction) were the $\mathrm{BDI}(M=.36, S D=.42, \alpha=.93)$ and the Revised UCLA Loneliness Scale $(M=1.72, S D=.46, \alpha=.90)$. Neither active nor passive Facebook use predicted changes on these measures $(p s>.24)$. The measures reported in the text are those that were theoretically motivated and directly informed by our previous research (Kross et al., 2013). Participants engaged in a pilot study after Phase 3, the outcomes of which have no bearing on the current results.
} 
Facebook online communication, and direct interactions) the total number of observations equals 8,336 as this analysis compares the mean of four variables that were observed 2,084 times.

We tested for mediation using 1-1-1 multilevel mediation analyses as all variables in the mediation model (i.e., affect, passive Facebook usage, and envy) were measured at Level 1. Specifically, we examined whether the link between passive Facebook usage at $\mathrm{T}_{1-2}$ and affect at $\mathrm{T}_{2}$ controlling for affect at $\mathrm{T}_{1}$ was mediated by envy at $\mathrm{T}_{1-2}$. The rationale and steps involved in 1-1-1 multilevel mediation analysis are similar to standard ordinary least squares mediation analysis but the estimation procedure is more challenging (for technical details, see Bolger \& Laurenceau, 2013). Following Bolger and Laurenceau (2013), all variables in the mediation model were group-mean centered, each path in the mediation model was allowed to vary randomly across participants and significance testing was performed using $z$ tests. Unstandardized regression weights are reported. A unique feature of multilevel mediation analysis (compared with ordinary least squares mediation analysis) is that the covariance between the random parts of the paths that together constitute the indirect effect is also considered to be part of the mediation pathway. However, in the present study this covariance was not significantly different from zero (covar $=.00, p=.97$ ) and will therefore not be discussed further.

We tested for moderation by examining whether each moderator variable was related to the slope of $\mathrm{T}_{1-2}$ active or passive Facebook usage when predicting $T_{2}$ affect, controlling for $T_{1}$ affect. When the moderator was measured twice (i.e., during Phase 1 and 3) the average of both assessments were used in this analysis. Data from two persons who scored more than 3.5 SDs above the sample mean on the BDI were excluded from the BDI moderation analyses; data from one person who scored more than 3.5 SDs below the sample mean on perceived Facebook support were excluded from the moderation analyses based on perceived Facebook support. The relationship between mean passive and active Facebook usage and life satisfaction was assessed using ordinary least squares regressions because these data were not nested.

\section{Results}

How often do people engage in different types of social interaction? We first examined how frequently participants engaged in the different types of social interaction we measured. As Figure 2 illustrates, people interacted "directly" with other people more frequently than any other type of social interaction, $t \mathrm{~s}(8332) \mathrm{s}>12.85, p \mathrm{~s}<.001$. They also used Facebook passively more than they used it actively or engaged in non-Facebook online social network activity, $t s(8332)>5.64, p s<.001$. The frequency of active Facebook usage and non-Facebook online social network usage did not differ, $t(8332)=.23, p=.82$. Table 4 presents the correlations between each of these different types of social interaction.

Does type of Facebook use predict declines in affective wellbeing over time? To address this question, we examined whether passive or active Facebook usage during the time period separating two text messages predicted how participants felt at Time 2, controlling for how they felt at Time 1. Replicating Study

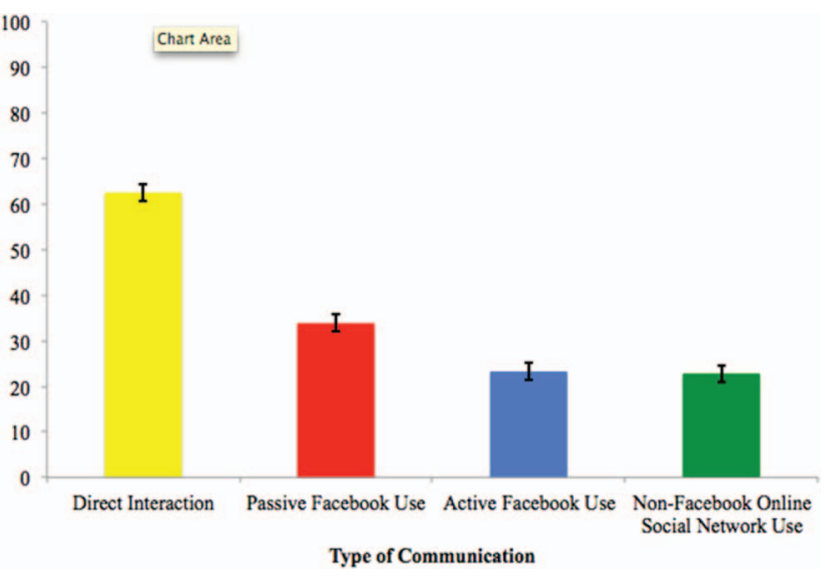

Figure 2. Type of communication frequency. Bars represent the mean amount of time participants engaged in each type of communication. Error bars represent $+/-$ one standard error. See the online article for the color version of this figure.

1, passive Facebook usage predicted declines in how good people felt over time, but active Facebook usage did not (see Table 5). Importantly, the reverse pathway-affect predicting changes in passive Facebook use-was not significant, $B=-.06, S E=.04$, $t(1605)=-1.54, p=.12,95 \%$ CI $[-.13, .02]$, indicating that people did not use Facebook passively more depending on how they felt.

To quantify the magnitude of the effect size characterizing the relationship between passive Facebook usage and changes in affect over time, we examined how much people's affect levels changed on trials when they did not engage in any passive Facebook usage (i.e., a score of 0 on the passive Facebook usage variable) compared with when they engaged in this behavior intensely (i.e., a score of 100 on the passive Facebook usage variable). ${ }^{4}$ Multiplying the regression weight obtained from this analysis by 100 revealed that people felt 5\% worse when they engaged passive Facebook usage " $a$ lot" during the time period separating any two affect assessments compared to when they did not use Facebook passively at all.

Passive Facebook usage also remained a significant predictor of changes in affective well-being when controlling for the other social interaction variables we assessed: non-Facebook online social network usage, active Facebook use and direct social interaction. As Table 5 illustrates, the only additional variable that was significantly related to changes in affective well-being over time in this analysis was direct social interaction. Replicating previous research (Kross et al., 2013), direct social interaction predicted increases in affective well-being over time.

Passive Facebook usage did not interact with direct social interaction, active Facebook usage, or non-Facebook online social

\footnotetext{
${ }^{4}$ The majority of participants reported using Facebook passively "a lot" during some intervals and "not at all" during other intervals as reflected by the mean range of passive Facebook usage scores across participants $(M=$ $81.78, S D=15.44)$
} 
Table 4

Correlations Between Key Measures

\begin{tabular}{lcccc}
\hline \multicolumn{1}{c}{ Variable } & 1 & 2 & 3 & 4 \\
\hline 1. Non-Facebook online social & & & & \\
$\quad$ network use & - & $.37^{* * * *}$ & $.50^{* * * *}$ & -.10 \\
2. Active Facebook use & $.39^{* * * * *}$ & - & $.55^{* * * *}$ & -.10 \\
3. Passive Facebook use & $.37^{* * * *}$ & $.47^{* * * *}$ & - & $-.16^{*}$ \\
4. Direction interaction & .02 & .07 & .00 & - \\
\hline
\end{tabular}

Note. Correlations above the dashed diagonal line represent withinperson correlations obtained from multi-level analyses. Correlations below the dashed line represent between-person correlations.

${ }^{*} p<.05 .{ }^{* * * *} p<.0001$.

network usage to predict any of the results $(p s>.12) .{ }^{5}$ In addition, controlling for the length of time between any two text messages did not substantively alter the relationship between passive Facebook usage and changes in affect over time.

Do individual differences moderate the relationship between passive Facebook use and declines in affective well-being? The relationship between passive Facebook usage and changes in affective well-being was not moderated by any of the individual differences we assessed, including: participants' number of Facebook friends, their perceptions of Facebook network support, depressive symptoms, loneliness, gender, self-esteem, or their motivation for using Facebook ( $p s \geq .08){ }^{6}$

Does envy mediate the relationship between passive Facebook use and declines in affective well-being? We performed multilevel mediation analyses (Bolger \& Laurenceau, 2013) to examine whether envy mediates the relationship between passive Facebook usage and declines in how good people feel over time. These analyses, all of which controlled for Time 1 affect, provided evidence to support mediation. Specifically, passive Facebook usage predicted envy $(\mathrm{B}=.10, S E=.02, \mathrm{z}=4.87, p<.0001$, $95 \%$ CI $[.06, .14])$, and envy predicted declines in affective wellbeing $(\mathrm{B}=-.27, S E=.04, \mathrm{z}=6.94, p<.0001,95 \% \mathrm{CI}$ $[-.35,-.19])$. Critically, the indirect relationship between passive Facebook usage and changes in affective well-being through envy was significant $(\mathrm{B}=-.03, S E=.01, \mathrm{z}=3.05, p<.01,95 \% \mathrm{CI}$ $[-.04,-.01])$. In contrast, the direct relationship between passive Facebook usage and changes in affective well-being was not significant when envy was controlled for $(\mathrm{B}=-.03, S E=.02$, $\mathrm{z}=1.45, p=.15,95 \% \mathrm{CI}[-.07 ; .01])$. The reverse mediation pathway (i.e., envy $\rightarrow$ passive Facebook usage $\rightarrow$ affect) was likewise not significant $(\mathrm{B}=-.003, S E=.01, \mathrm{z}=.31, p=.76$, $95 \%$ CI $[-.02 ; .01])$.

Does type of Facebook use predict declines in cognitive well-being over time? Replicating Study 1, neither active $(\mathrm{B}=-.003, S E=.01, t(73)=-.40, p=.69,95 \%$ CI $[-.02$, $.01])$ nor passive $(\mathrm{B}=.006, S E=.01, t(73)=.82, p=.42,95 \%$ CI $[-.01, .02])$ Facebook usage predicted decreases in cognitive well-being (i.e., life satisfaction). The relationship between passive or active Facebook usage and life satisfaction was not moderated by participants' number of Facebook friends, their perceptions of Facebook network support, depressive symptoms, loneliness, gender, self-esteem, or their motivation for using Facebook ( $p s \geq .09$ ).

\section{General Discussion}

This research adds to work indicating that interacting with Facebook has negative implications for subjective well-being (Krasnova et al., 2013; Kross et al., 2013). It extends this work by demonstrating that passive (but not active) Facebook usage specifically undermines affective well-being and does so by enhancing envy.

It is noteworthy that participants in Study 2 used Facebook passively about $50 \%$ more than they used it actively. This suggests that people spend most of their time on Facebook engaging in a behavior that undermines their affective well-being. It also explains why measures of overall Facebook activity have revealed a negative relationship with subjective well-being (Kross et al., 2013).

Neither active nor passive Facebook usage predicted declines in life satisfaction in these studies. This was surprising given prior work linking Facebook usage with diminished life satisfaction (e.g., Krasnova et al., 2013; Kross et al., 2013). One explanation for this null finding is that we measured changes in cognitive well-being over shorter time spans than previous research (Kross et al., 2013). It is also possible that active and passive Facebook usage do not reliably influence life satisfaction.

Although some evidence suggests that certain types of active Facebook usage enhance positive outcomes such as social connectedness (Burke \& Kraut, 2014; Deters \& Mehl, 2013; Ellison, Steinfield, \& Lampe, 2007), we did not observe any relationship between active Facebook usage and well-being in the current studies. ${ }^{7}$ These are not, however, incompatible results. Instead, they likely reflect independent effects - that is, actively interacting with one's colleagues online may build social ties, but still leave a person feeling badly when they learn about their peers' accom-

\footnotetext{
${ }^{5}$ As in Study 1, we examined whether type of Facebook usage influenced loneliness. Both types of Facebook usage predicted increases in loneliness over time when adding both predictors to the model separately (active: $\mathrm{B}=.08, S E=.03, t(1606)=2.86, p<.01,95 \%$ CI $[.02, .13]$; passive: $\mathrm{B}=.10, \mathrm{SE}=.02, t(1606)=4.38, p<.0001,95 \% \mathrm{CI}[.05, .15])$ However, when active and passive Facebook usage were simultaneously included as predictors, passive Facebook usage significantly predicted an increase in loneliness $(\mathrm{B}=.10, S E=.03, t(1605)=3.51, p<.001,95 \%$ CI $[.04, .15])$; active Facebook usage $\operatorname{did} \operatorname{not}(\mathrm{B}=.02, S E=.03, t(1605)=$ $.54, p=.58,95 \%$ CI $[-.04, .08])$. Conversely, loneliness at $\mathrm{T}_{1}$ did not predict active $(\mathrm{B}=.00, S E=.03, t(1605)=.05, p=.96,95 \% \mathrm{CI}[-.06$, $.06])$ or passive Facebook usage $(\mathrm{B}=.05, S E=.04, t(1605)=1.34, p=$ $.18,95 \%$ CI $[-.02, .12])$ at $\mathrm{T}_{1-2}$ when controlling for Facebook usage at $\mathrm{T}_{0-1}$. Thus, it was not the case that people used Facebook more because they felt lonely.

${ }^{6}$ None of these individual differences predicted active or passive Facebook use $(p s>.09)$.

${ }^{7}$ Prior research (Deters \& Mehl, 2013) indicates that directing people to post more status updates (i.e., one type of active Facebook usage) leads to reduced feelings of loneliness. To examine whether this effect replicated in our data, we coded status updates from Participants Facebook walls and examined whether updates $(0=$ no status update, $1=$ at least one status update) during $\mathrm{T}_{1-2}$ predicts loneliness at $\mathrm{T}_{2}$ controlling for loneliness at $\mathrm{T}_{1}$. There was no effect of status updates on changes in loneliness $(\mathrm{B}=-1.12, S E=2.73, t(1332)=.41, p=.68,95 \%$ CI $[-6.48,4.24])$ Similarly, status updates did not predict changes in affective well-being $(\mathrm{B}=-2.02, S E=2.68, t(1332)=.76 p=.45,95 \% \mathrm{CI}[-7.27,3.22])$. One potential explanation for these null findings is that we observed a floor effect on this variable. Multiple status updates were infrequent; there were no updates posted around $95 \%$ of the time. Because of this, we treated status updates as a binary predictor.
} 
Table 5

Unstandardized Regression Weights of Predictors of Affect at T2 Controlling for Affect at T1

When Adding the Predictors to the Multilevel Model Separately $(D F=1,606)$ or Simultaneously $(D F=1,603)$

\begin{tabular}{|c|c|c|c|c|c|c|}
\hline \multirow[b]{2}{*}{ Predictor } & \multicolumn{3}{|c|}{ Separately } & \multicolumn{3}{|c|}{ Simultaneously } \\
\hline & $\mathrm{B}$ & $S E$ & $95 \% \mathrm{CI}$ & B & $S E$ & $95 \% \mathrm{CI}$ \\
\hline Passive Facebook use & $-.05^{* *}$ & .02 & {$[-.09,-.02]$} & $-.05^{*}$ & .02 & {$[-.09,-.001]$} \\
\hline Active Facebook use & -.02 & .02 & {$[-.06, .03]$} & .02 & .02 & {$[-.03, .07]$} \\
\hline Non-Facebook online & & & & & & \\
\hline social network use & $-.05^{*}$ & .03 & {$[-.11,-.01]$} & -.03 & .03 & {$[-.08, .03]$} \\
\hline Direct interaction & $.14^{* * * * *}$ & .02 & {$[.10, .19]$} & $.14^{* * * *}$ & .02 & {$[.09, .18]$} \\
\hline
\end{tabular}

plishments. Juxtaposing these findings suggests that whether interacting with Facebook is "good" or "bad" for people depends on the nature of the outcome variable one is examining. A key challenge for future research is to identify when (and why) interacting with this technology leads to positive versus negative socioemotional outcomes.

In terms of practical significance, in Study 1 our experimental manipulation led people in the passive Facebook usage condition to feel approximately $9 \%$ worse at the end of the day compared with baseline. In Study 2, intense passive Facebook usage predicted a $5 \%$ decrease in affective well-being over time (i.e., from one text message to the next). Together, these results suggest that passive Facebook usage predicts substantive declines in subjective well-being in both the lab and in daily life. In this vein, it is important to recognize that affective well-being is a multiply determined outcome. Thus, identifying any factor that systematically influences it is important in our view (for more detailed discussion, see Kross et al., 2013).

One question raised by these findings concerns why people continue to passively use Facebook if engaging in this process undermines their affective well-being. Although the current data do not address this question, we can think of at least three explanations for this phenomenon. First, a growing literature suggests that Facebook (and social network sites more generally) have addictive properties (Ryan, Chester, Reece, \& Xenos, 2014). It is well established that people engage in addictive behaviors despite their negative implications. Second, interacting with Facebook helps people connect with others and keep abreast of events in their community (Ellison et al., 2007). It is possible that people's motivation to "stay in touch" outweigh concerns they have over how interacting with this technology influences their feelings. Finally, it is possible that people are not aware of how interacting with Facebook influences their emotions. Examining which, if any of these explanations explain why people continue to use Facebook despites its negative emotional implications is an important future challenge.

\section{Caveats}

Three caveats are in order before concluding. First, in Study 1 we observed an effect of passive Facebook use at the end of the day, not immediately after the manipulation was administered. In Study 2, we also observed a delayed relationship between passive Facebook usage and affective well-being declines-our analyses were inherently "lagged" in that we examined how passive Facebook use during one time interval (e.g., between 3 p.m. and 5 p.m.) influenced how people felt at the end of that interval (at 5 p.m.), controlling for how they felt initially (at 3 p.m.). Together, these two sets of findings suggest that passive Facebook usage has a delayed, not immediate, effect on how people feel. ${ }^{8}$ Why might this be? We suspect that people need time to reflect on the information they passively consume on Facebook for envy to build in ways that ultimately impact the way they feel. Future research is needed to explore this issue and should consider focusing on rumination as an intervening variable.

Second, although the current research begins to shed light on the mechanisms that explain how Facebook use undermines affective well-being, other mechanisms likely also play a role in jointly mediating this relationship. For example, recent work suggests that people may perceive the time they spend using Facebook as meaningless (Sasioglou \& Greitmeyer, 2014), which may also play a role in explaining how passive Facebook usage undermines affective well-being. Future research is needed to explore this issue and is important for refining our understanding of how passive Facebook usage influences well-being.

Finally, participants in the current studies were young adults. Future research is needed to examine whether the current findings generalize to other populations including, older and younger $\mathrm{Fa}$ cebook users, people who use Facebook excessively, and individuals from other cultures.

\section{Concluding Comment}

In a recent interview with the New York Times (Dominus, 2013), Randi Zuckerberg, the sister of Facebook's founder was asked, "What are you most guilty of on Facebook?" Her response, "I'm a marketer, and sometimes I almost can't take it out of my personal life. I've had friends call me and say, 'Your life looks so amazing.' And I tell them: 'I'm a marketer; I'm only posting the moments that are amazing." "Though we all "present" ourselves in daily life

\footnotetext{
${ }^{8}$ As noted in the text, controlling for the amount of time elapsed between (a) the manipulation of Facebook usage and the end of day measurement of affect in Study 1, and (b) the consecutive measurements of affect in Study 2 did not substantively influence the results. These findings, in conjunction with the absence of an immediate effect of manipulating Facebook usage on affect in Study 1, suggest that although some delay is necessary for passive Facebook usage to influence affect, the exact duration of this delay is less important.
} 
(Goffman, 1959), the current findings suggest that how people do so on Facebook creates an environment that is difficult to passively navigate without negatively influencing how we feel.

\section{References}

Barash, V., Ducheneaut, N., Isaacs, E., \& Bellotti, V. (2010). Faceplant: Impression (mis)management in Facebook status updates. Proceedings of the Fourth International AAAI Conference on Weblogs and Social Media, 20, 7-210.

Beck, A. T., Ward, C. H., Mendelson, M., Mock, J., \& Erbaugh, J. (1961). An inventory for measuring depression. Archives of General Psychiatry, 4, 561-571. http://dx.doi.org/10.1001/archpsyc.1961.01710120031004

Bolger, N., \& Laurenceau, J. (2013). Intensive longitudinal methods: An introduction to diary and experience sampling research. New York, NY: Guilford Press.

Brickman, P., \& Bulman, R. J. (1977). Pleasure and pain in social comparison. In J. Suls \& R. L. Miller (Eds.), Social comparison processes: Theoretical and empirical perspectives (pp. 149-186). New York, NY: Wiley and Sons.

Burke, M., \& Kraut, R. (2014). Growing closer on Facebook: Changes in tie strength through site use. ACM CHI 2014: Conference on Human Factors in Computing Systems.

Burke, M., Marlow, C., \& Lento, T. (2010). Social network activity and social well-being. Proceedings of the SIGCHI Conference on Human Factors in Computing Systems.

Chou, H. T., \& Edge, N. (2012). "They are happier and having better lives than I am:" The impact of using Facebook on perceptions of others' lives. Cyberpsychology, Behavior, and Social Networking, 15, 117-121. http://dx.doi.org/10.1089/cyber.2011.0324

Cutrona, C. E. (1989). Ratings of social support by adolescents and adult informants: Degree of correspondence and prediction of depressive symptoms. Journal of Personality and Social Psychology, 57, 723-730. http://dx.doi.org/10.1037/0022-3514.57.4.723

Deters, F. G., \& Mehl, M. R. (2013). Does posting Facebook status updates increase or decrease loneliness? An online social networking experiment. Social Psychological \& Personality Science, 4, 579-586. http:// dx.doi.org/10.1177/1948550612469233

Diener, E., Emmons, R. A., Larsen, R. J., \& Griffin, S. (1985). The Satisfaction With Life Scale. Journal of Personality Assessment, 49, 71-75. http://dx.doi.org/10.1207/s15327752jpa4901_13

Dominus, S. (2013, November 1). Randi Zuckerberg: I really put myself out there. The New York Times, pp. MM14, Sunday Magazine.

Ellison, N. B., Steinfield, C., \& Lampe, C. (2007). The benefits of Facebook "friends:" Social capital and college students' use of online social network sites. Journal of Computer-Mediated Communication, 12, 1143-1168. http://dx.doi.org/10.1111/j.1083-6101.2007.00367.x

Ellsworth, P. C. (1995). The right way to study emotion. Psychological Inquiry, 6, 213-216. http://dx.doi.org/10.1207/s15327965pli0603_5

Gilbert, D. T., Giesler, R. B., \& Morris, K. A. (1995). When comparisons arise. Journal of Personality and Social Psychology, 69, 227-236. http://dx.doi.org/10.1037/0022-3514.69.2.227

Goethals, G. R. (1986). Social comparison theory: Psychology from the lost and found. Personality and Social Psychology Bulletin, 12, 261278. http://dx.doi.org/10.1177/0146167286123001
Goffman, E. (1959). The presentation of self in everyday life. Westminster, MD: Random House.

Koval, P., Kuppens, P., Allen, N. B., \& Sheeber, L. (2012). Getting stuck in depression: The roles of rumination and emotional inertia. Cognition and Emotion, 26, 1412-1427. http://dx.doi.org/10.1080/02699931.2012 .667392

Krasnova, H., Wenninger, H., Widjaja, T., \& Buxmann, P. (2013). Envy on Facebook: A hidden threat to users' life satisfaction? 11th International Conference on Wirtchaftsinformatik (WI).

Kross, E., Verduyn, P., Demiralp, E., Park, J., Lee, D. S., Lin, N., . . . Ybarra, O. (2013). Facebook use predicts declines in subjective wellbeing in young adults. PLoS ONE, 8, e69841. http://dx.doi.org/10.1371/ journal.pone.0069841

Mehdizadeh, S. (2010). Self-presentation 2.0: Narcissism and self-esteem on Facebook. Cyberpsychology, Behavior, and Social Networking, 13, 357-364. http://dx.doi.org/10.1089/cyber.2009.0257

Newman, M. W., Lauterbach, D., Munson, S. A., Resnick, P., \& Morris, M. E. (2011). It's not that I don't have problems, I'm just not putting them on Facebook: Challenges and opportunities in using online social networks for health. ACM 2011 conference on Computer supported cooperative work.

Nisbett, R. E., \& Wilson, T. D. (1977). Telling more than we know: Verbal reports on mental processes. Psychological Review, 84, 231-259. http:// dx.doi.org/10.1037/0033-295X.84.3.231

Robinson, M. D. C., \& Clore, G. L. (2002). Belief and feeling: Evidence for an accessibility model of emotional self-report. Psychological Bulletin, 128, 934-960.

Rosenberg, M. (1965). Rosenberg self-esteem scale (RSE). Acceptance and Commitment Therapy, Measures Package, 61.

Russell, D., Peplau, L. A., \& Cutrona, C. E. (1980). The revised UCLA Loneliness Scale: Concurrent and discriminant validity evidence. Journal of Personality and Social Psychology, 39, 472-480. http://dx.doi .org/10.1037/0022-3514.39.3.472

Ryan, T., Chester, A., Reece, J., \& Xenos, S. (2014). The uses and abuses of Facebook: A review of Facebook addiction. Journal of Behavioral Addictions, 3, 133-148. http://dx.doi.org/10.1556/JBA.3.2014.016

Sagioglou, C., \& Greitemeyer, T. (2014). Facebook's emotional consequences: Why Facebook causes a descrease in mood and why people still use it. Computers in Human Behavior, 35, 359-363. http://dx.doi .org/10.1016/j.chb.2014.03.003

Salovey, P., \& Rodin, J. (1984). Some antecedents and consequences of social-comparison jealousy. Journal of Personality and Social Psychology, 47, 780-792. http://dx.doi.org/10.1037/0022-3514.47.4.780

Smith, R. H., \& Kim, S. H. (2007). Comprehending envy. Psychological Bulletin, 133, 46-64. http://dx.doi.org/10.1037/0033-2909.133.1.46

Wood, J. V. (1996). What is social comparison and how should we study it? Personality and Social Psychology Bulletin, 22, 520-537. http://dx .doi.org/10.1177/0146167296225009

Received October 14, 2014

Revision received November 26, 2014

Accepted January 6, 2015 